\title{
SINGLE VERSUS MULTIPLE HORTICULTURAL OPERATIONS WITH GNSS ASSISTED STEERING
}

\author{
Marco Benetti, Francesco Saltarin, Stefano Zanon, Michele Zucal \\ University of Padova, Italy \\ marcobenetti.agri@gmail.com
}

\begin{abstract}
In the recent years the increasing implementation of Global Navigation Satellite Systems (GNSS) hasgreatly enhanced the ability of farmers to apply precision management approaches. Many research studies demonstrate how such technologies can bring great benefits to extensive agriculture and viticulture, while specific studies are still lacking in the case of horticultural crops. The aim of the present work is to make a comparison on the performances of single and multiple operations carried out using manual and assisted steering. The experimental study was carried out in an 8 ha area, planted with watermelon and pumpkin. Specifically bed formers, mulching machines and seed drills were analyzed, considering three different approaches: single operations, semi-combined operations and fully combined operations. Data were collected on direct and indirect costs, operation times and working capacity.
\end{abstract}

Keywords: assisted steering, Global Navigation Satellite Systems, precision horticulture.

\section{Introduction}

Precision agriculture is an approach to agricultural and livestock production based on quantification and management of the spatial or individual variability allowing optimization of resource efficiency, productivity, profitability and environmental sustainability [1-3]. Many advancements in machinery and technologies used for precision agriculture have been donein the last few years and implemented, mainly for extensive crops. The same technologies have had relevant applications also in the case of different farms as, for instance, in vineyards, orchards or in horticultural productions, however, in this case only few research studies have been published on actual efficiency and profitability.

Many technologies can contribute to the success of precision agricultureapproaches: soil and crop sensors [4], three-dimensional instruments [5;6], robotics and automation [7;8], decision support systems [9], etc. Above all, tractor guidance and steering control is certainly the most mature of agricultural precision technologies, having been in commercial use for about two decades. These systems enable tractors to be precisely positioned in the field with minimal driver interaction [1], potentially allowingimprovements of machine and driver performances. With respect to the machinery, it is possible to minimize skips or overlaps during seeding, spraying, fertilizing and harvesting, and to better localize the machine for controlled traffic, inter-row seeding or strip tillage. With reference to the driver, steering attention is reduced in such a way that operations of implements can be better monitored, and fatigue reduced. Such improvements permit a reduction of input costs (agrochemicals, working hours, machine and maintenance costs,...) and an increase in the overall efficiency of agricultural operations and of environmental performances allowing improvements of agricultural product sustainability [10;11].

Despite low diffusion, implementation of positioning and of automatic steering systems in horticultural farming has the potential to bring not only some of the advantages seen for herbaceous crops (as the reduction of the driver stress or optimization of positioning), but also other specific benefits, such as automatic localization of different varieties orthe possibility of executing combined operations. The latter is particularly relevant in relation to mechanization. Indeed, due to the fact that some horticultural operations are often carried out in quick succession, the possibility of combining some operations is interesting not only for time and costs reduction but also for minimization of soil compaction. While in conventional systems the combination of operations is limited by the fact that the driver cannot simultaneously control the tractor and two or more implements, in the case of automatic steering systems such limitation is overcome.

The aim of this paper is to compare the efficiency and the economical convenience of single and multiple operations carried out in two typical horticultural crops (watermelon and pumpkin) through manual and assisted steering. 


\section{Materials and methods}

\section{Experimental site}

For the present research a set of experiments was carried out in a private farm in north-eastern Italy in a typical Po Valley field $(45.1346 \mathrm{~N}, 11.5866 \mathrm{E}) .8$ ha fields were selected, cultivated with watermelon (4ha) and pumpkin (4 ha). Watermelon and pumpkin production system presented in this research employs raised beds covered with black plastic mulch ( 240 rows, $100 \mathrm{~m} \mathrm{long}$ ).

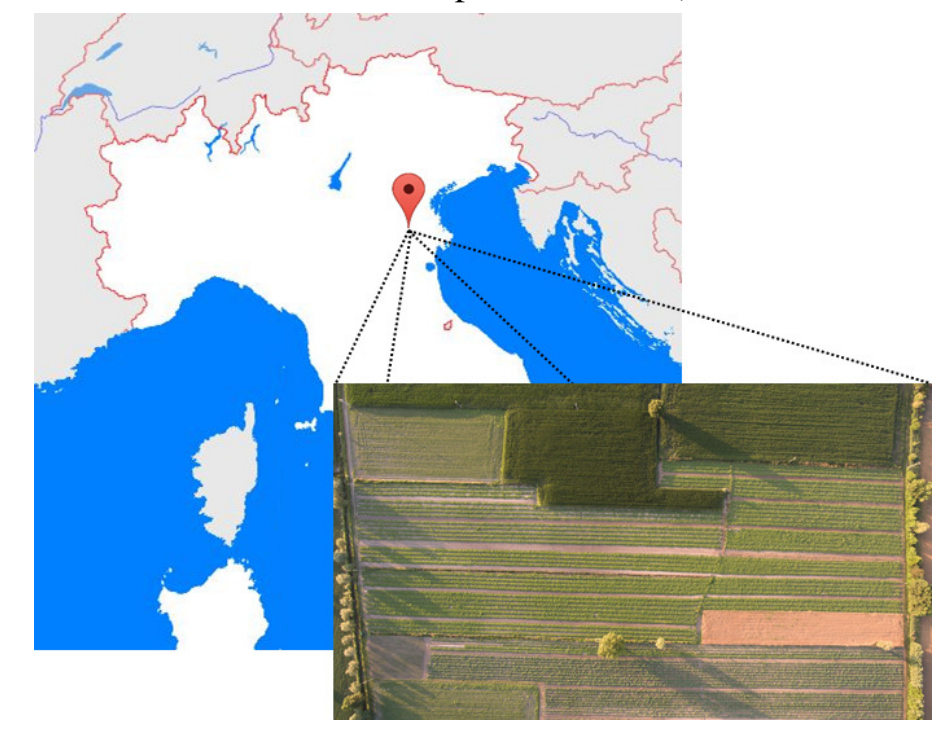

Fig. 1. Horticultural field considered for experimental tests

\section{Equipment}

Operations considered for the present experiment included three main operations: bed shaping, mulching and transplanting. The used machinery is reported in Table 1, along with the main characteristics.

Table 1

\section{Equipment used for the experimental study}

\begin{tabular}{|c|c|c|c|c|c|}
\hline Equipment & Model & Weight, kg & Width, m & Length, $\mathrm{m}$ & Other technical data \\
\hline Tractor & $\begin{array}{c}\text { New Holland } \\
\mathrm{t} 4.75 \\
\end{array}$ & 2850 & 1.95 & 3.88 & $\begin{array}{c}\text { Maximum power: } 55 \mathrm{~kW} \\
\text { Turning radius: } 3.8 \mathrm{~m} \\
\end{array}$ \\
\hline Bed shaping & HortechAB & 260 & 1.60 & 1.25 & $\begin{array}{l}\text { Needed power: } 22 \mathrm{~kW} \\
\text { Speed: } 5 \mathrm{~km} \cdot \mathrm{h}^{-1}\end{array}$ \\
\hline Mulching & HortechP & 320 & 1.50 & 1.70 & $\begin{array}{l}\text { Needed power: } 30 \mathrm{~kW} \\
\text { Speed: } 4.5 \mathrm{~km} \cdot \mathrm{h}^{-1}\end{array}$ \\
\hline Transplanting & HortechOver & 250 & 1.80 & 2.00 & $\begin{array}{l}\text { Needed power: } 37 \mathrm{~kW} \\
\text { Speed: } 4 \mathrm{~km} \cdot \mathrm{h}^{-1}\end{array}$ \\
\hline Monitor & $\begin{array}{l}\text { Trimble } \\
\text { FM750 }\end{array}$ & - & - & - & \multirow{2}{*}{$\begin{array}{l}\text { Precision: } 2.5 \mathrm{~cm} \\
\text { Accuracy: } 20 \mathrm{~cm}\end{array}$} \\
\hline $\begin{array}{c}\text { Steering } \\
\text { system }\end{array}$ & $\begin{array}{l}\text { Trimble } \\
\text { EZ Pilot }\end{array}$ & - & - & - & \\
\hline
\end{tabular}

\section{Scheduled operations}

As mentioned above, the experimental study has been focused on evaluation of the efficiency and of economical convenience of single operations compared to multiple operations combined in one passage thanks to implementation of the automatic steering system. To this end, the following parameters where considered and measured or estimated:

1. single and combined operations working speeds;

2. timing: implements set up (hook up and unhook, installation of mulch film, transfers, plant tray upload) and turning operations at the end of the row;

3 . single and combined operations fuel consumption. 
Additionally, costs of the used equipment and manpower were considered in the analysis.

For sake of simplicity, here "BMT" is used in order to indicate combined bed shaping, mulching and transplanting operations, "BM $+\mathrm{T}$ " refers to combined bed shaping and mulching and separated transplanting, while " $\mathrm{B}+\mathrm{M}+\mathrm{T}$ " stands for separated single operations.

\section{Results and discussion}

Operation times analysed during the field tests allowed estimation of the working capacity for different management approaches. The main results are summarized in Table 2.

Table 2

Operation time for different management strategies on the 8 ha experimental field

\begin{tabular}{|c|c|c|c|c|}
\hline $\begin{array}{c}\text { Management } \\
\text { strategy }\end{array}$ & Acronym & Operations & $\begin{array}{c}\text { Operation } \\
\text { times, h }\end{array}$ & $\begin{array}{c}\text { Manpower, } \\
\text { h }\end{array}$ \\
\hline Single operations & $\mathrm{B}+\mathrm{M}+\mathrm{T}$ & $\begin{array}{c}1 \text { bed shaping + 1 mulching + } \\
1 \text { transplanting }\end{array}$ & 52.02 & 88.03 \\
\hline $\begin{array}{c}\text { Two combined } \\
\text { operations }\end{array}$ & $\mathrm{BM}+\mathrm{T}$ & $\begin{array}{c}1 \text { bed shaping \& mulching + } \\
1 \text { transplanting }\end{array}$ & 39.07 & 78.14 \\
\hline $\begin{array}{c}\text { Three combined } \\
\text { operations }\end{array}$ & BMT & $\begin{array}{c}1 \text { bed shaping \& mulching \& } \\
\text { transplanting }\end{array}$ & 22.98 & 45.96 \\
\hline
\end{tabular}

It should be noted that the total manpower is different from the total operation times, since mulching and transplanting request one driver onboard the tractor and one person assisting the implement operation (control and replacement of polymer films and plant tray upload). It is clearly evident how integration and combination of multiple operations in one passage allow reduction of working times with total saving as high as $\mathbf{5 7} \%$ for machinery and $49 \%$ for manpower.

Timing needed for the operations has to be combined with the equipment costs in order to evaluate the total operating costs for the three different proposed approaches. The economic analysis results are summarized in Table 3.

Table 3

Total costs for single, two combined and three combined operations

\begin{tabular}{|c|c|c|c|c|c|c|c|}
\hline Costs & Tractor & Bedshaper & Mulcher & Transpl. & $\begin{array}{l}\text { Bedshaper } \\
\text { + Mulcher }\end{array}$ & BMT & $\begin{array}{c}\text { Steering } \\
\text { system }\end{array}$ \\
\hline $\begin{array}{c}\text { Initial value, } \\
\text { EUR }\end{array}$ & 31000 & 1000 & 3000 & 3000 & 5000 & 8800 & 7800 \\
\hline $\begin{array}{l}\text { Depreciation, } \\
\text { EUR } \cdot \text { year }^{-1}\end{array}$ & 2635 & 85 & 255 & 255 & 425 & 220 & 195 \\
\hline $\begin{array}{c}\text { Average life, } \\
\text { years }\end{array}$ & 10 & 10 & 10 & 10 & 10 & 10 & 6 \\
\hline $\begin{array}{c}\text { Interests, } \\
\text { EUR } \cdot \text { year }^{-1}\end{array}$ & 775 & 25 & 75 & 75 & 125 & 220 & 195 \\
\hline $\begin{array}{l}\text { Other costs, } \\
\text { EUR } \cdot \text { year }^{-1}\end{array}$ & 372 & 5 & 15 & 15 & 25 & 44 & 39 \\
\hline $\begin{array}{l}\text { Main costs, } \\
\text { EUR } \cdot \text { year }^{-1}\end{array}$ & 3782 & 115 & 345 & 345 & 575 & 1012 & 1534 \\
\hline $\begin{array}{c}\text { Maintenance, } \\
\text { EUR }^{-1} \mathrm{~h}^{-1}\end{array}$ & 3.66 & 1.33 & 3.36 & 3.36 & 4.16 & 5.68 & 0.90 \\
\hline $\begin{array}{l}\text { Manpower, } \\
\text { EUR }^{-1} \mathrm{~h}^{-1}\end{array}$ & 18 & - & 18 & 18 & 18 & 18 & - \\
\hline $\begin{array}{l}\text { Total costs, } \\
\text { EUR } \cdot \mathrm{h}^{-1}\end{array}$ & 30.66 & 8.09 & 42.92 & 37.79 & 52.42 & 67.68 & 4.74 \\
\hline
\end{tabular}


Combining the costs of the tractor, of single or combined operations and the steering system, linear models can be produced, indicating a fixed cost, which is ranging between 1167 EUR (in the $\mathrm{B}+\mathrm{M}+\mathrm{T}$ case) and 1361 EUR (BMT case), and variable costs, which are ranging $249.4 \mathrm{EUR} \cdot \mathrm{ha}^{-1}$ $(\mathrm{B}+\mathrm{M}+\mathrm{T}), 228.3 \mathrm{EUR} \cdot \mathrm{ha}^{-1}(\mathrm{BM}+\mathrm{T})$ and $126.0 \mathrm{EUR} \cdot \mathrm{ha}^{-1}(\mathrm{BMT})$. The models are presented in Figure 2a, showing how the implementation of the combined BMT approach is profitable (compared to single operations) with a farm size larger than 2 ha; similarly, bed shaping combined with mulching is profitable whenever the farm size is larger than 7 ha. Considering the return on the initial investment, on a planning horizon of 10 years, an average 11 ha farm is needed in the case of the BMT combination approach, while 45 ha are needed in the case of the $\mathrm{BM}+\mathrm{T}$ like management approach. Due to manpower and machinery savings, the BMT is clearly recommendable, allowing maximization of profits even in the case of small farms. In the case of large farms, the combination of only two operations can be profitable, while the automatic steering system can bring additional benefits in improvement of the efficiency and reduction of overall working times.
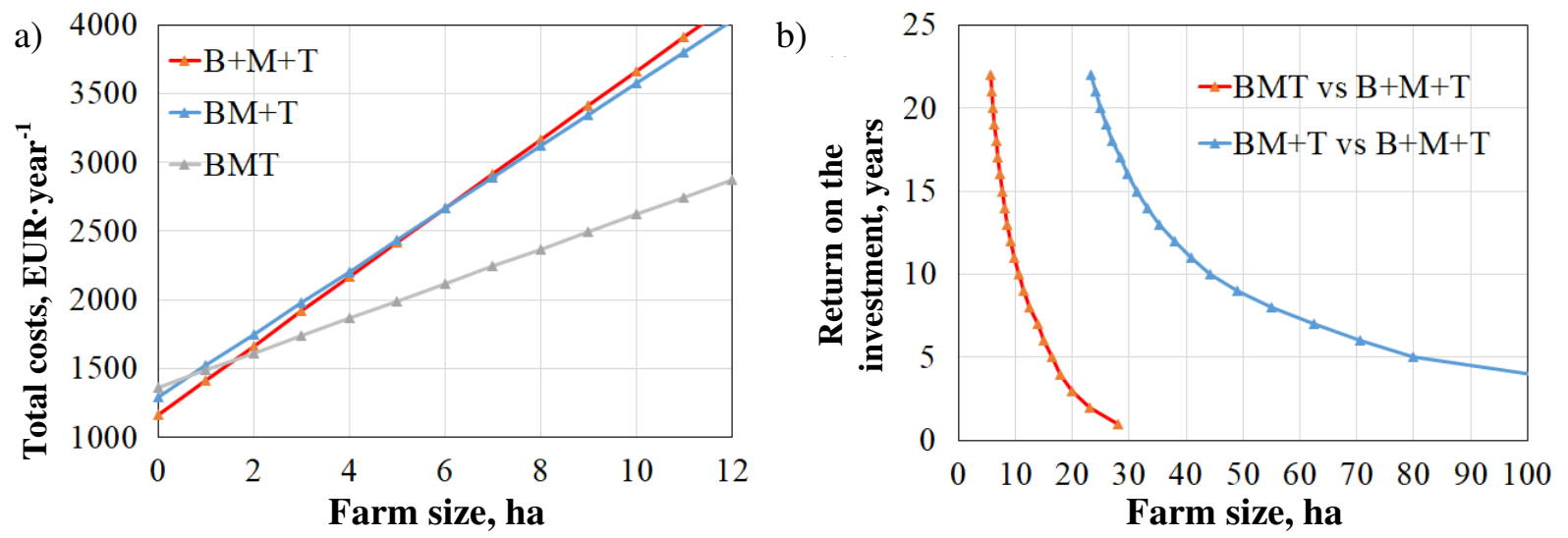

Fig. 2. Total costs for three analysed management approaches as function of farm size (a) and average time for return on investment as function of farm size (b)

\section{Conclusions}

Assisted steering can have positive results in horticultural mechanization. While a manual control is subject to performance decay due to the increase of fatigue, decreased attention, decreased visibility, the assisted steering system guarantees more stable performance, regardless of the skill of the driver and his psycho-physical state, even in the case of large farms. Assisted steering can be successfully applied in order to allow combination of multiple operations. Compared to single managed operations, such approach can provide relevant benefits in terms of time and economic savings. The reported field tests highlighted how assisted steering and combination of operations can bring to:

1. increase of the efficiency with the working time reduction up to $51 \%$ (inclusive of machinery and manpower);

2. reduction of costs up to $123 \mathrm{EUR} \cdot \mathrm{ha}^{-1}$.

Such improvement can guarantee a return on the investment for advanced steering equipment, in particular in the case of medium or large farms, with a total cultivated area larger than 10 ha.

\section{Acknowledgements}

The authors wish to thank Prof. Francesco Marinello for the supervision of the research activity and the assistance in the definition of the proposed model.

\section{References}

[1] Barnes A.P., Soto I., Eory V., Beck B., Balafoutis A., Sánchez B., Vangeyts J., Fountas S., Van der Walf T., Gómez-Barbero M. Exploring the adoption of precision agricultural technologies: A cross regional study of EU farmers. Land Use Policy, vol. 80, pp. 163-174.

[2] Pezzuolo A., Dumont B., Sartori L., Marinello F., De Antoni Migliorati M., Basso B. Evaluating the impact of soil conservation measures on soil organic carbon at the farm scale. Computer and Electronics in Agriculture, vol. 135, 2017, pp. 175-182. 
[3] Mattioli A., Boscaro D., Dalla Venezia F., Santacroce F.C., Pezzuolo A., Sartori L., Bolzonella D. Biogas from residual grass: A territorial approach for sustainable bioenergy production. Waste and biomass valorization, vol. 8, 2017, pp. 2747-2756.

[4] Dubbini M., Pezzuolo A., De Giglio M., Gattelli M., Curzio L., Covi D., Yezekyan T., Marinello F. Last generation instrument for agriculture multispectral data collection. CIGR Journal, vol. 19, 2017, pp. 158-163.

[5] Pezzuolo A., Guarino M., Sartori L., González L.A., Marinello F. On-barn pig weight estimation based on body measurement by means of a Kinect v1 sensor. Computer and Electronics in Agriculture, vol. 148, 2018, 29-36.

[6] Pezzuolo A., Guarino M., Sartori L., Marinello F. A feasibility study on the use of a structured light depth-camera for three-dimensional body measurements of dairy cows in free-stall barns. Sensors, vol. 18, 2018, pp. 673.

[7] Baillie C.P., Lobsey C.R., Antille D.L.,McCarthy C.L.,Thomasson J.A. A review of the state of the art in agricultural automation. Part III: Agricultural machinery navigation systems. 2018 ASABE Annual International Meeting. ASABE, St. Joseph, MI (2018), p. 1.

[8] Escolà A., Martínez-Casasnovas J.A., Rufat J., Arnó J., Arboné, A., Sebé F., Pascual M., Gregorio E., Rosell-Polo J.R.Mobile terrestrial laser scanner applications in precision fruticulture/horticulture and tools to extract information from canopy point clouds. Precision Agriculture, vol. 118, 2017, pp. 111-132.

[9] Pezzuolo A., Basso B., Marinello F., Sartori L. Using SALUS model for medium and long term simulations of energy efficiency in different tillage systems. Applied Mathematical Sciences, vol. 8/129-132, 2014, pp. 6433-6445.

[10]Zude-Sasse M., Fountas S., Gemtos T.A., Abu-Khalaf N. Applications of precision agriculture in horticultural crops. European Jornal Horticultural Science,vol. 81, 2016, pp. 78-90.

[11] Borsato E., Tarolli P., Marinello F. Sustainable patterns of main agricultural products combining different footprint parameters. Journal of cleaner production, vol. 179, 2018, pp. 357-367. 